\title{
Tolerance for cougars diminished by high perception of risk
}

\author{
Aliah Adams Knopff ${ }^{1}$, Kvle H. Knopff ${ }^{2}$ and Colleen Cassady St. Clair ${ }^{3}$
}

\begin{abstract}
In North America, both human and cougar populations are expanding and increasingly sharing the same space, including modified landscapes viewed by people as their "backyard." Low tolerance for cougars in modified landscapes has been identified as a key factor that could restrict continued cougar range expansion in North America, or even reverse some of the gains made by cougar populations in recent decades. To better understand factors influencing tolerance and identify opportunities to improve conservation prospects for cougars, we implemented a questionnaire in west-central Alberta, where both human and cougar populations have increased over the past 20 years and where we had developed a resource selection function for cougars from telemetry data. Respondents overestimated risk from cougars, and more than half believed cougars posed the same or greater risk as driving a car, even though only one Albertan has been killed by a cougar in the last century and hundreds die in car accidents each year. Although respondents valued cougars highly, they indicated that cougars belonged in the wilderness and not near their homes. We predicted that tolerance for cougars would be negatively correlated with increased probability of cougar selection near the respondent's home, but our prediction was not supported. Although such correlations have been reported at broader spatial scales, we suggest they may break down at finer scales. Other factors, such as education, were important drivers of tolerance for cougars in Alberta. Our results suggest that education undertaken to improve large carnivore conservation should focus on accurately defining the risks and ecological benefits resulting from maintaining cougars on the landscape. Education may also need to focus on the importance of nonwilderness habitats (i.e., the rapidly expanding backyard) as an important part of long-term conservation and continued range expansion and repatriation of adaptable large carnivores, such as cougars.
\end{abstract}

Key Words: Alberta, carnivore management; coexistence; conflict; cougar; Puma concolor; risk; RSF; tolerance

\section{INTRODUCTION}

Maintaining and recovering populations of large carnivores on increasingly human-dominated landscapes are significant conservation challenges (Treves and Karanth 2003). Much attention has been paid to the problems of habitat loss or degradation as a source of large carnivore declines (Ripple et al. 2014), but recent evidence indicates that many large carnivores are more resilient to anthropogenic landscape change than is commonly assumed (Athreya et al. 2013, Chapron et al. 2014, Knopff et al 2014). In such cases, the most important limitation to large carnivore conservation is caused by the danger (real and perceived) carnivores pose to livestock and people (Thirgood et al. 2005), not by a lack of wilderness or protected areas (LópezBao et al. 2015). Threats by carnivores to humans and their livelihoods have caused people to persecute carnivores throughout recorded history, resulting in local and regional extirpation of many species (Woodroffe 2000, å2001, Treves and Karanth 2003, Ripple et al. 2014) including gray wolves (Canis lupus, Coleman 2004), grizzly bears (Ursus arctos ssp., Brown 1996), and cougars in North America (Puma concolor, Logan and Sweanor 2000). This history suggests that human tolerance is a fundamental component of conservation planning for large carnivores and invites greater knowledge of the factors that enhance or inhibit tolerance (Ripple et al. 2014).

Tolerance for carnivores increases with the intrinsic value that a person holds for wildlife (Kellert et al. 1996, Mattson and Clark 2009) and an individual's socioeconomic status (NaughtonTreves et al. 2003, Mattson and Clark 2009). By contrast, tolerance is demonstrably lower when people associate wildlife with high levels of risk (Treves and Karanth 2003), and perception of risk can influence tolerance as much as actual losses to predators (Naughton-Treves and Treves 2005). In general, tolerance is lower for people who have regular contact with carnivores that could affect them adversely (Kellert et al. 1996, Naughton-Treves et al. 2003), which may be the reason that close proximity to carnivore populations typically reduces tolerance (Manfredo et al. 1998, Williams et al. 2002, Karlsson and Sjöström 2007). Reduced tolerance near carnivore populations is especially relevant to jurisdictions where expanding carnivore and human populations meet. In many of these areas, humans and large carnivores have not shared the landscape in decades, and the perceptions of carnivores by people may include especially large differences between actual and perceived risk.

In North America, the link between tolerance and large carnivore conservation is aptly demonstrated by the history of cougars. Perceived as pests by early European settlers, cougars were extirpated from most of eastern North America (except Florida) and their numbers in other areas were drastically reduced (Logan and Sweanor 2000, Gill 2009). Pervasive antipredator sentiment was endorsed by governments, which facilitated cougar removal using bounties and poisoning programs, restricting cougar range to remote areas, and maintained low cougar numbers until the middle of the 20th century (Kellert et al. 1996, Anderson et al. 2009).

Attitudes and government policies began to change in the $1960 \mathrm{~s}$ and 1970 s, primarily as a result of an increasingly urbanized society that had little direct contact with large carnivores (Williams et al. 2002, Manfredo et al. 2003). People also began to value large carnivores as big game species (Treves 2009) and icons of wilderness (Gill 2009). Scientists increasingly recognized

${ }^{1}$ Talus Environmental Consulting, ${ }^{2}$ Golder Associates Ltd., ${ }^{3}$ University of Alberta 
the ecological role top predators play in regulating ecosystems (Terborgh et al. 2001, Ripple and Beschta 2006, Ripple et al. 2014). Today, most wildlife management agencies in western North America work to maintain healthy cougar populations (Cougar Management Guidelines Working Group 2005, Anderson et al. 2009). In some states, public ballots have even been used to place restrictions on cougar hunting, or halt it altogether (Mattson and Clark 2009). Changing public opinion and refined cougar management practices resulted in growing cougar populations that have recently begun recolonizing portions of their former range (Anderson et al. 2009, Knopff et al. 2013).

Ironically, cougar recovery has been so successful in some places that more frequent conflict with people may be shifting public perception and increasing lethal management. A combination of recovering cougar populations and increasing rural and exurban development means that people now regularly share landscapes with cougars, providing greater opportunity for negative cougarhuman interactions (Torres et al. 1996, Logan and Sweanor 2001, Baron 2004). Complaints about cougars filed with local fish and wildlife agencies have increased in several jurisdictions (Torres et al. 1996, Cougar Management Guidelines Working Group 2005, Lambert et al. 2006), and cougar attacks on humans also appear to be increasing (Beier 1991, Torres 2005, Penteriani et al. 2016). This new wave of conflict between cougars and humans in North America has been identified as an important complication for the conservation of the species (Hornocker 2009). In several states, population reduction to lessen conflict with people is again a clear objective of official management plans (e.g., Oregon Department of Fish and Wildlife 2006), and Lambert et al. (2006) suggest that negative perceptions of cougars have led to declining cougar populations in parts of Oregon, Washington, and British Columbia. Wildlife managers urgently need tools to help maintain populations of cougars and other carnivores in ways that simultaneously support (1) the benefits of ecological regulation, (2) responsibility for the protection of biodiversity, and (3) human security in shared landscapes. Education can be a powerful tool for fostering coexistence (e.g., Manfredo et al. 2003, Bruskotter and Wilson 2014), but only when the factors that promote it are understood (Slagle et al. 2013).

The objective of our study was to determine which of several factors most influences tolerance of cougars in Alberta, Canada, where cougar populations have been increasing since the late 1980s (Knopff et al. 2013). We were particularly interested in the effects of (1) respondent attitude and experience, (2) perceptions of risk, and (3) the likelihood of encounter with a cougar near the respondent's home. We addressed these objectives by surveying residents of west-central Alberta, an area where cougar populations appear to have increased and nonhunting cougar mortalities associated with conflicts rose rapidly during 1991-2010 (Knopff et al. 2013). Specifically, we used a questionnaire to investigate the impact on tolerance of five different factors: value for cougars, risk perception, socioeconomic factors, social associations, and experience with cougars. To test the effect of proximity to cougar activity on tolerance, we linked questionnaire responses to the relative probability that a cougar would select the area around a respondent's home, estimated using a resource selection function. We used this relationship to test the hypothesis that carnivore tolerance declines as overlap with people increases (Manfredo et al. 1998, Riley and Decker 2002, Williams et al. 2002, Karlsson and Sjöström 2007).

\section{METHODS}

\section{Study area}

We studied public attitudes toward cougars in Clearwater County, a portion of west-central Alberta where there has been extensive population growth for both cougars (Knopff et al. 2013) and people (Duke et al. 2003). The majority of the county's approximately 12,000 residents live in the town of Rocky Mountain House (65\%) and the hamlet of Caroline (4\%), with the remainder living in smaller hamlets (e.g., Nordegg, population 70) or on ranches or small acreages (Fig. 1). The cougar population in Clearwater County may have increased by more than $250 \%$ in the last two decades (Knopff 2010). Ungulate prey, primarily white-tailed and mule deer (Odocoileus virginianus and O. hemionus) but also elk (Cervus canadensis), moose (Alces alces), and bighorn sheep (Ovis canadensis), were abundant throughout the study area, and were the primary food source for cougars (Knopff et al. 2010). Livestock and pets also were prevalent in the eastern portion of the county, but were infrequently killed by cougars (Knopff et al. 2010).

Fig. 1. Map of Clearwater County depicting the gradient of human population density. The lightest grey areas have a density of $<1$ buildling per $\mathrm{km}^{2}$ while the darkest are $>200$ buildings per $\mathrm{km}^{2}$. Also shown is the divide between public and private land, lakes and rivers (white), and the three principal towns: Rocky Mountain House (RMH), Caroline, and Nordegg.

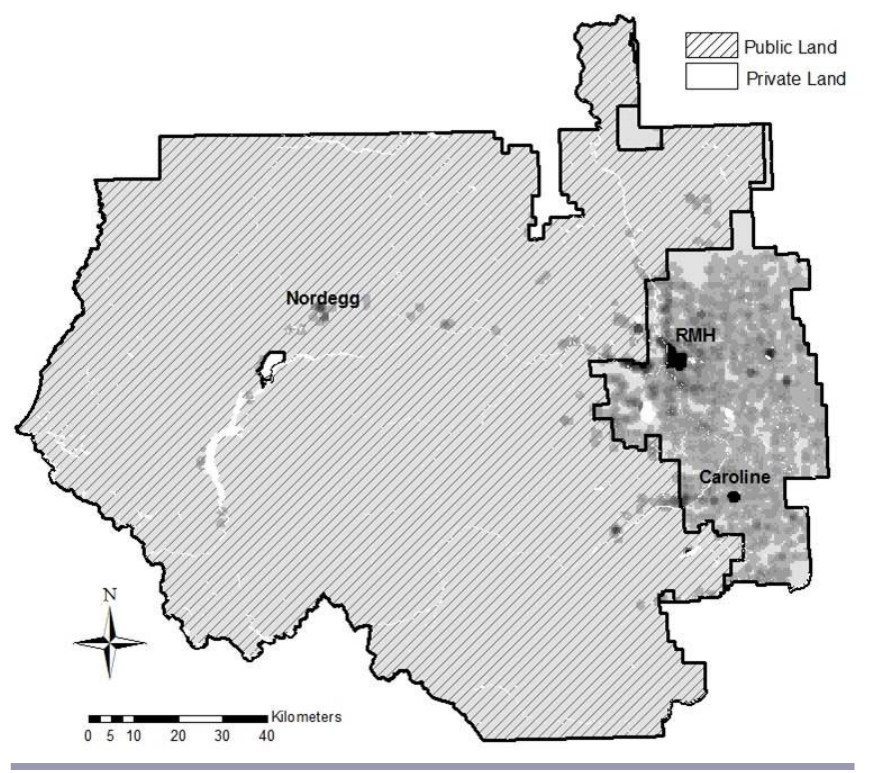

\section{Survey instrument and administration}

We used a survey to assess the factors influencing tolerance by Clearwater County residents for cougars. The survey instrument was a drop-off, mail-back questionnaire designed to identify respondents' tolerance for cougars, perceived risk associated with cougars, and value for cougars. In addition, we requested 
Table 1. Definitions of variables used in questionnaire analysis.

\begin{tabular}{|c|c|c|c|}
\hline Variable & Type & Definition & Category \\
\hline TOLERANCE & $\begin{array}{l}\text { Continuous between } \\
1-5\end{array}$ & $1=$ low tolerance for coexisting with cougars, $5=$ high tolerance & $\begin{array}{c}\text { TOLERANCE } \\
\text { (Response variable) }\end{array}$ \\
\hline VALUE & $\begin{array}{l}\text { Continuous between } \\
1-5\end{array}$ & $1=$ low value for cougars, $5=$ high value for cougars & VALUE \\
\hline RISK & $\begin{array}{l}\text { Continuous between } \\
\qquad 1-5\end{array}$ & $1=$ low risk perception, $5=$ high risk perception & RISK \\
\hline Schooling & Categorical & $\begin{array}{l}\text { Level of education: } 1=\text { high school, } 2=\text { some college or university, } 3= \\
\text { undergraduate degree, or } 4=\text { graduate degree }\end{array}$ & Socio-econ \\
\hline Ranching & Binary & Is the respondent a rancher? $(1=$ yes, $0=$ no $)$ & Socio-econ \\
\hline Livestock & Binary & Does the respondent own livestock? $(1=$ yes, $0=$ no $)$ & Socio-econ \\
\hline Age & Continuous & Years of age & Socio-econ \\
\hline Children & Binary & Are children present $(1=$ yes, $0=$ no $)$ & Socio-econ \\
\hline Gender & Binary & Male or female $(1=$ female, $0=$ male $)$ & Socio-econ \\
\hline Pets & Binary & Does the respondent own a pet? $(1=$ yes, $0=$ no $)$ & Socio-econ \\
\hline Story & Binary & $\begin{array}{l}\text { Has the respondent been exposed to a story about cougars from a friend? }(1= \\
\text { yes, } 0=\text { no) }\end{array}$ & Experience \\
\hline Presentation & Binary & $\begin{array}{l}\text { Has the respondent been exposed to a presentation about cougars? }(1=\text { yes, } \\
0=\text { no) }\end{array}$ & Experience \\
\hline Personal interaction & Binary & Has the respondent had a personal interaction with a cougar? $(1=$ yes, $0=$ no $)$ & Experience \\
\hline Media exposure & Binary & $\begin{array}{l}\text { Has the respondent been exposed to cougars through the media? }(1=\text { yes, } 0= \\
\text { no) }\end{array}$ & Experience \\
\hline Hunting & Binary & Is the respondent a hunter? $(1=$ yes, $0=$ no $)$ & Activities \\
\hline Outdoor recreation & Binary & Does the respondent participate in outdoor activities $(1=$ yes, $0=$ no $)$ & Activities \\
\hline Proximity & Continuous & $\begin{array}{l}\text { RSF score at a } 500-\mathrm{m} \text { radius around the home, } 0 \text { for lowest relative probability } \\
\text { of cougar use, } 1 \text { for highest }\end{array}$ & Proximity \\
\hline
\end{tabular}

demographic and personal information (e.g., age, sex, education, activities, pet and livestock ownership, previous experience with cougars, organizational affiliations) to investigate how these variables affected tolerance. The questionnaire included a background-information section with a photograph of a cougar and eight phrases outlining identification and natural history characteristics of cougars. The design and implementation of the questionnaire were approved by the University of Alberta Arts, Science \& Law Research Ethics Board (application number 1763, CDH08-51).

Two sets of questions were used to quantify TOLERANCE, which was the primary response variable for this study (Table 1). The first set of questions asked whether humans and cougars should coexist in (1) rural residential areas, (2) human settlements in national parks, and (3) urban areas. The second set asked whether respondents thought it was appropriate to shoot a cougar if (1) they saw a cougar on their property, (2) they saw a cougar near their home, (3) a cougar threatened them or another person, (4) a cougar threatened a pet, and (5) a cougar threatened livestock. Responses to questions in each set were scaled using five options from strongly agree to strongly disagree. Separate averages were calculated for each set of questions, and the mean of the two was used to estimate TOLERANCE.

Other questions posed to respondents were designed to quantify various attributes and perspectives of respondents that might affect tolerance for cougars (Table 1). The responses to most questions were used directly to quantify respondent attributes (e.g., respondent age, previous experience with cougars), but in two cases perspectives were estimated from a suite of questions.

One set of questions was used to generate the variable RISK, which describes the perception respondents have of the threat cougars pose. We asked respondents to rank the likelihood of the following scenarios on a five-point scale: (1) encountering a cougar near their home, (2) being attacked by a cougar near their home, (3) their pet being attacked by a cougar near their home, and (4) their livestock being attacked by a cougar. We averaged responses for these four questions to estimate RISK. Possible responses to questions about RISK were scaled using five categorical options ranging from very likely to unlikely.

We then used the average score from three questions to generate the variable VALUE, which describes the degree to which each respondent valued cougars. The questions were as follows: "The presence of cougars is a sign of a healthy environment," "It is important to me that cougars persist in Alberta for future generations," and "It is important to me to know that cougars exist, even if I never see one in the wild." Possible responses to questions about VALUE were scaled using five categorical options ranging from strongly agree to strongly disagree.

We asked additional questions to help better understand RISK and VALUE. We estimated relative risk perception for cougars (i.e., the risk respondents assigned to cougars relative to the risk they assigned to other potentially dangerous factors affecting their lives) by asking respondents to compare the risk posed by cougars to the risk of being injured in a car accident. We also asked respondents whether they believed their overall quality of life increased by having cougars near their homes, whether the number of cougars within $1 \mathrm{~km}$ of their home should increase, and whether their overall feelings toward cougars were positive or negative.

The survey was administered during May 2008. We contacted 479 randomly selected households in Clearwater County by telephone to request their participation. The following week, we 
distributed the questionnaire to the homes of willing participants $(n=335)$ and included a preaddressed postage-paid envelope for survey return. Surveys were numbered, and at the time of dropoff the location of the participant's home was recorded using a handheld GPS (Fig. 1) and assigned to that number. Participants who did not return the questionnaire within one month $(n=138)$ were contacted again via telephone to remind them of the survey, and an additional questionnaire was mailed. A total of 247 questionnaires were returned, yielding a response rate of $52 \%$ of all households contacted and $74 \%$ of willing participants.

\section{Cougar habitat selection}

To link the questionnaires to the relative probability of cougar habitat selection around a participant's home, we applied a resource selection function (RSF) derived as part of a separate study (Knopff et al. 2014). Predicted relative probabilities of cougar landscape selection at a 25-m pixel size for the study area were rescaled between 0 and 1 (Manly et al 2002). We then calculated an average RSF score for a window with a 500-m radius around the location of each respondent's home to represent the probability of cougar selection of the area around the home and compared this score to TOLERANCE.

\section{Factors affecting TOLERANCE}

We used a multiple working hypothesis framework (Burnham and Anderson 2002) to evaluate explanatory variables as predictors of TOLERANCE by survey respondents. We generated seven a priori models and used Akaike's information criterion (AIC $)$ to evaluate the weight of evidence for each model. Each candidate model included a combination of six groups of variables hypothesized by others to influence tolerance. Each group included different numbers of predictor variables (Table 1), and groups were included or excluded from candidate models as cohesive units (Table 2). Predictor variable groups were (1) socioeconomic variables commonly used in studies of human attitudes toward wildlife, (2) variables describing experience with cougars, (3) the value respondents associated with cougars, (4) variables describing the outdoor activities in which respondents participated, (5) risk respondents associated with cougars, and (6) RSF scores describing the relative probability of cougar selection of habitat within $500 \mathrm{~m}$ of the respondent's home. To avoid multicollinearity, variables correlated at $|r|>0.7$ were not used in the same model. Log-likelihoods for each model were calculated using the generalized linear model with a Gaussian link in STATA 10 (StataCorp, College Station, Texas, USA).

Table 2. A priori candidate models used to explain tolerance for cougars in Clearwater County, Alberta.

\begin{tabular}{cl}
\hline \hline $\begin{array}{c}\text { Model } \\
\text { no. }\end{array}$ & Model structure \\
\hline 1 & RISK + Proximity \\
2 & Proximity + Experience + Activity \\
3 & Socio-econ + RISK \\
4 & VALUE + Activity + Experience \\
5 & RISK + Proximity + Experience \\
6 & VALUE + Socio-econ \\
7 & VALUE + RISK + Proximity + Socio-econ + Experience + \\
& Activity \\
\hline
\end{tabular}

To interpret the relative importance of each variable retained in the top model, we standardized values for each covariate in each pixel with a z-score transformation so that each variable had a mean of 0 and a standard deviation of 1 (Gotelli and Ellison 2004).

The standardized coefficients reflect the amount of change in tolerance that accompanies 1 standard deviation change in the raw covariate score. Thus, the absolute value of the standardized coefficients is proportional to that covariate's importance in the model.

Finally, to test if RISK was linked to probability of cougar selection near respondents' homes, we regressed RISK against the average RSF score within a 500-m radius of the respondent's home and assessed the strength of the correlation using Pearson's r.

\section{RESULTS}

\section{Respondent characteristics}

Respondents to our survey tended to be older residents (average age $=54$ years $[$ SD 13], range 20-89 years) who had lived in Clearwater County for a long time (mean $=29$ years $[$ SD 20]). More respondents lived in rural areas $(81 \%)$ than urban areas, more were male (58\%) than female, and most did not have children living at home $(73 \%)$. Most respondents had completed high school $(75 \%)$, many attended at least one year of college or university ( $41 \%$ ), and some attended university for $\geq 4$ years $(15 \%)$. Almost all respondents owned some kind of domestic animal or livestock $(90 \%)$, but fewer than half described themselves as ranchers $(28 \%)$ or as owning livestock $(22 \%)$. Almost all participated in outdoor activities $(90 \%)$, and many were hunters $(35 \%)$. Few respondents were associated with formal organizations, whether for hunting $(9 \%)$, conservation $(5 \%)$, or more general outdoor activity $(9 \%)$. More than half of the respondents reported having a personal experience with a cougar $(54 \%)$, and most of these were described as strictly positive $(51 \%)$ or both positive and negative (34\%) as opposed to strictly negative $(15 \%)$. For respondents who had not had a personal experience with a cougar, information about cougars was commonly derived from media reports $(84 \%)$ and stories told by acquaintances $(82 \%)$, whereas presentations $(45 \%)$ or books about cougars $(30 \%)$ were accessed by fewer respondents.

\section{Respondent TOLERANCE}

Respondents generally agreed that cougars and humans should coexist in national and provincial parks $(77 \%$ agreement for coexistence), but were divided about whether coexistence should occur in rural areas (36\% agree, $40 \%$ disagree, $24 \%$ neutral) and were generally opposed to coexistence in urban areas $(84 \%$ disagree). Tolerance for interactions with cougars decreased with the severity of the hypothetical interaction. Whereas a minority of respondents (18\%) supporting shooting a cougar if it was observed on their property but away from their home, this number increased sharply if pets, livestock, or people were threatened. Most respondents thought that cougars should be shot if they placed pets, livestock, or people in danger (Fig. 2). 
Fig. 2. The tolerance of survey respondents to cougar-human interaction scenarios. Respondents were asked how much they agreed that shooting a cougar would be the appropriate course of action for each scenario. $\mathrm{SA}=$ strongly agree, $\mathrm{A}=$ agree, $\mathrm{N}$ $=$ neutral, $\mathrm{D}=$ disagree, $\mathrm{SD}=$ strongly disagree.

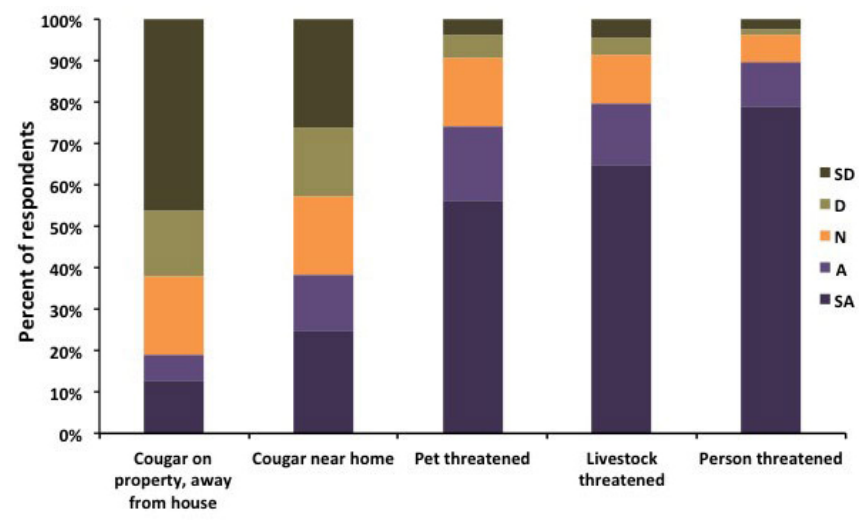

\section{Perceived RISK}

Despite believing that cougars did not commonly use areas within $1 \mathrm{~km}$ of their home $(75 \%)$, a majority of respondents still believed that it was likely or very likely that they would encounter a cougar near their home $(64 \%)$ and that some type of conflict was a possibility. Sixty percent of respondents believed their livestock might be attacked by a cougar, $50 \%$ felt their pets were in danger, and $25 \%$ believed it was at least somewhat likely they would be attacked by a cougar near their home (Fig. 3). In terms of relative risk, $31 \%$ of respondents believed that they faced higher risk of being attacked by a cougar than being injured in a car accident, and $24 \%$ felt the risk was about the same.

Fig. 3. The likelihood that respondents to the Clearwater County Cougar Survey believed that they would have an interaction with a cougar near their home. $\mathrm{VL}=$ very likely, $\mathrm{L}=$ likely, $\mathrm{SL}=$ somewhat likely, $\mathrm{U}=$ unsure, $\mathrm{VU}=$ very unlikely.

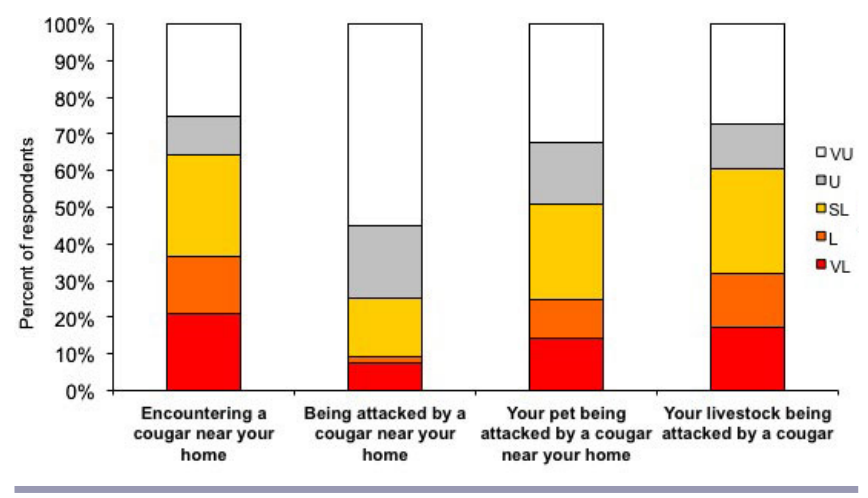

\section{Cougar VALUE}

In general, respondents demonstrated high VALUE for cougars and thought that the presence of cougars was important for a healthy environment ( $65 \%$ agree) and that the continued presence of cougars in Alberta was important ( $76 \%$ agree). However, most respondents did not feel that the presence of cougars near their homes increased their overall quality of life (57\% disagree), and only a small minority thought that the number of cougars within $1 \mathrm{~km}$ from their home should increase $(3 \%)$. However, few respondents considered their overall feelings toward cougars to be negative $(15 \%)$.

\section{Cougar selection near respondents' homes}

Respondents included people from urban (19\%) and rural (81\%) areas within Clearwater County. The relative probability of cougar selection within $500 \mathrm{~m}$ of respondents' homes varied more than 1,000 -fold $\left(\mathrm{x}_{234}=0.82, \mathrm{SE}=0.27\right)$. The respondent's home with the lowest relative probability of cougar habitat selection within a 500-m radius was located in Rocky Mountain House, and the home surrounded by land with the highest relative probability of cougar selection was located approximately $15 \mathrm{~km}$ north of Rocky Mountain House along the banks of the North Saskatchewan River. The relative probability of cougar selection near homes was retained in the top model, but contrary to our prediction, the effect of the variable on tolerance was weakly positive (Table 3). Another unexpected result was that RISK correlated poorly with probability of cougar selection (Fig. 4, $\left.r_{235}^{2}=0.06, \mathrm{p}<0.05\right)$.

Table 3. Descriptive statistics and ordered generalized linear regression results for the top model predicting tolerance for cougars in Clearwater County, Alberta.

\begin{tabular}{lcccccc}
\hline \hline Variable & $\begin{array}{c}\text { Standard } \\
\text { coefficient }\end{array}$ & Coefficient & Mean & $\begin{array}{c}\text { Standard } \\
\text { deviation }\end{array}$ & Min. Max. \\
\hline VALUE & 0.33 & 0.35 & 4.16 & 0.93 & 1 & 5 \\
Hunting & -0.15 & -0.31 & 0.35 & 0.48 & 0 & 1 \\
Age & -0.14 & -0.01 & 54.34 & 13.38 & 20 & 89 \\
RISK & -0.11 & -0.09 & 2.51 & 1.21 & 1 & 5 \\
Schooling & 0.10 & 0.10 & 2.37 & 1.00 & 1 & 4 \\
Ranching & -0.09 & -0.20 & 0.28 & 0.45 & 0 & 1 \\
Children & -0.09 & -0.20 & 0.27 & 0.45 & 0 & 1 \\
Pets & 0.07 & 0.17 & 0.81 & 0.39 & 0 & 1 \\
Personal & 0.06 & 0.11 & 0.53 & 0.50 & 0 & 1 \\
Story & -0.05 & -0.17 & 0.89 & 0.31 & 0 & 1 \\
Proximity & 0.05 & 0.18 & 0.82 & 0.28 & 0 & 0.99 \\
Livestock & 0.04 & 0.07 & 0.49 & 0.50 & 0 & 1 \\
Presentation & 0.03 & 0.05 & 0.52 & 0.50 & 0 & 1 \\
Media & -0.02 & -0.06 & 0.89 & 0.31 & 0 & 1 \\
Gender & -0.02 & -0.04 & 0.42 & 0.49 & 0 & 1 \\
Outdoor & 0.00 & 0.00 & 0.91 & 0.29 & 0 & 1 \\
recreation & & & & & & \\
\hline
\end{tabular}

\section{Factors affecting TOLERANCE}

TOLERANCE was best explained by the model that incorporated all six variable classes (Table 4). The four covariates with the strongest influence on TOLERANCE were VALUE, hunting, age, and RISK. VALUE was positively associated with TOLERANCE and was by far the strongest predictor, with double the impact of hunting, which was the next strongest covariate and was negatively associated with TOLERANCE. RISK was negatively associated with TOLERANCE and was twice as important as personal experience with cougars or living in proximity to areas of higher probability of cougar selection. 
Table 4. Ordered generalized logistic models used to describe tolerance for coexisting with cougars in Clearwater County, Alberta. Model log-likelihood (LL), number of estimated parameters (K), Akaike's information criterion (AIC), AIC difference ( $\triangle \mathrm{AIC}$ ), and AIC weight (wi) are displayed.

\begin{tabular}{|c|c|c|c|c|c|c|}
\hline Rank & Variables & LL & $\mathrm{K}$ & $\mathrm{AIC}$ & $\Delta \mathrm{AIC}$ & $w_{i}$ \\
\hline 1 & $\begin{array}{l}\text { VALUE + RISK + Proximity + Socio-econ + Experience }+ \\
\text { Activity }\end{array}$ & -196.08 & 16 & 424.16 & 0.00 & 1.00 \\
\hline 2 & RISK + Proximity + Experience + Socio-econ & -219.70 & 13 & 465.40 & 41.24 & 0.00 \\
\hline 3 & VALUE + Activity + Experience & -227.75 & 7 & 469.50 & 45.34 & 0.00 \\
\hline 4 & VALUE + Socio-econ & -234.45 & 8 & 484.90 & 60.74 & 0.00 \\
\hline 5 & Proximity + Experience & -245.06 & 5 & 500.12 & 76.00 & 0.00 \\
\hline 6 & Socio-econ + RISK & -252.90 & 8 & 521.80 & 97.63 & 0.00 \\
\hline 7 & RISK + Proximity & -262.46 & 2 & 528.91 & 104.76 & 0.00 \\
\hline
\end{tabular}

Fig. 4. Relationship between the amount of risk survey respondents from Clearwater County, Alberta, associated with coexisting with cougars and the probability of cougar selection for habitat within a 500-m radius around the respondent's home (resource selection function [RSF] score).

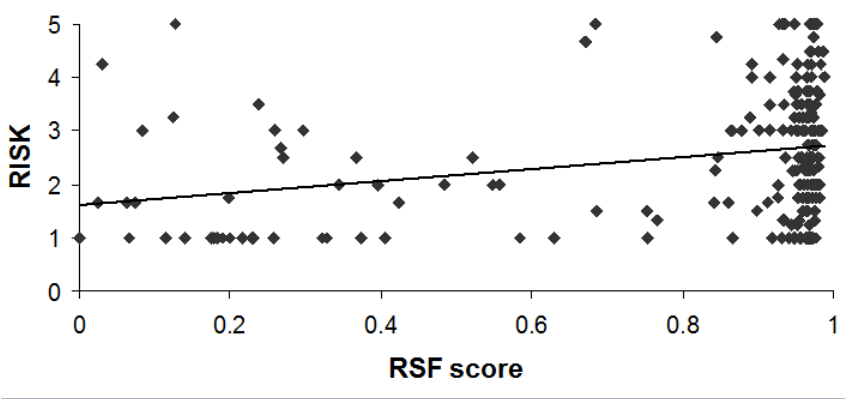

\section{DISCUSSION}

Antipredator sentiment can hamper conservation efforts and can be deeply ingrained in human culture, sometimes lasting centuries after predators have been extirpated (Kellert et al. 1996). For many North Americans, cougars are no longer seen as a threat to be controlled or a resource to be exploited; rather, they are valued for their ecological role and aesthetic beauty (Mattson and Clark 2009). Cougars can adapt to landscapes that are substantially modified by anthropogenic activities (Knopff et al. 2014), and whether or not cougars persist on such landscapes in the long term likely depends on the tolerance of the people occupying them. Based on 247 responses to our survey, we found that most rural Albertans value cougars highly, with a majority of individuals wanting to see cougars persist and believing that they play an important ecological role. Survey responses to our questions about value suggested that cougars may be tolerated by most respondents, at least in a general sense.

However, a different interpretation of tolerance emerged from responses to survey questions that were specific with respect to the potential for conflict with cougars in rural and urban areas. Respondents were clearly less willing to support cougar-human coexistence as the landscape became more populated by people and were more willing to shoot a cougar as the severity of a hypothetical conflict scenario increased. A prevailing sentiment was that cougars belonged in the "wilderness" and not close to homes. In other words, Clearwater County residents were supportive of cougar conservation so long as that did not involve their own backyards, a sentiment that appears to be common for large carnivores (Riley and Decker 2002, Ericsson et al. 2008). Because increasing rural and exurban development means that the size of the "backyard" in North American landscapes is growing, conservationists are challenged to understand how to foster coexistence on developing landscapes.

The amount of risk that people associated with cougars had an important impact on tolerance. Many authors have appreciated the negative relationship between perceived risk and human tolerance in the context of human-wildlife conflict (Decker et al. 2002, Røskaft et al. 2003) and even the presence of carnivores (Riley and Decker 2002, Naughton-Treves et al. 2003). Risk perception drove postsettlement persecution of carnivores by European Americans (Coleman 2004), and we found that risk perception was the fourth most important driver of tolerance for cougars in Alberta's Clearwater County.

Our study suggests that even rural residents who already live in cougar ranges are likely to overestimate the risk of conflict. More than half of the respondents $(55 \%)$ thought that coexisting with cougars posed at least the same amount of risk to their personal survival as driving a car, considerably higher than the $\sim 20 \%$ of respondents with a similar view of the threat of mortality from cougars versus driving in Montana (Riley 1998). These evaluations are profoundly different from the realities described by readily available statistics. In Alberta, only one person has been killed by a cougar in the past 100 years (Torres 2005), whereas there was an average of almost 400 human fatalities on roads per year in the five years before we conducted our survey (Alberta Transportation 2008). Livestock and pet depredations by cougars, although much more common than attacks on people, are also rare in Clearwater County (Knopff 2010).

The substantial overestimation of risk many people associated with cougars could be the result of a cognitive illusion, which occurs when rare events are so memorable and easily recalled that individuals overestimate their frequency (Kahneman and Tversky 1996). This illusion is more likely to occur precisely because fatal attacks by cougars are rare, which creates lasting media attention, thereby elevating perceived risks (Decker et al. 2002). This phenomenon reveals the important role played by the media in emphasizing, or not emphasizing, negative encounters that amplify a fear of carnivores (Gore and Knuth 2009, Penteriani et 
al. 2016). That fear is easily aroused because humans have a long evolutionary history with large carnivores that produces a natural, and rational, fear (Kruuk 2002). Supporting the retention of large carnivores in human-dominated landscapes will require human residents to evaluate risks accurately. The interaction between tolerance and risk perception is particularly relevant to the everincreasing overlap between cougars and people through much of western North America, where wildlife managers may have opportunities for proactive attention to perceptions of risk. This potential is already appreciated by many jurisdictions, which offer educational brochures, websites, interpretive events, and outreach activities to educate people about how to protect themselves, livestock, and pets from carnivores.

Tolerance for cougars is clearly influenced by perceptions of the risks they pose, not only to people and livestock, but also to ungulate populations, which are hunted for meat, valued intrinsically, and marketed for trophy hunting. Among our respondents, being a hunter was the second most important factor influencing tolerance for cougars, and hunters were substantially less tolerant than nonhunters. In their survey comments, a number of hunters expressed concern that cougars reduce game populations and that current numbers of deer and elk were low because there were too many cougars on the landscape. This result is also consistent with the findings of others: hunters that target ungulates are less tolerant of cougars because of perceived competition (Holsman 2000, Treves 2009). Alongside hunters, tolerance was lower for respondents who were older, less educated, or ranchers. These groups tend to hold more traditional views about carnivores, often seeing them not only as competitors for game, but also as threats to livestock or as an economic resource (Williams et al. 2002, Naughton-Treves et al. 2003, Mattson and Clark 2009).

We explored the hypothesis that respondents would be more likely to perceive high risk from cougars if they lived in areas where cougars were more likely to occur. This idea was based on the findings of others at larger spatial scales. Riley and Decker (2002) found that residents of Montana perceived lower risk from cougars in the eastern part of the state (where few cougars persist) relative to the western part (where cougars are common). Similarly, Karlsson and Sjöström (2007) found that tolerance of wolves in Sweden increased when the nearest wolf territory was at least $150 \mathrm{~km}$ from residents. Our results at the fine scale (i.e., variation in habitat selection within areas occupied by cougars) did not support this hypothesis; an RSF derived from GPS location data to predict the probability of selection by cougars within a 500-m radius from a residence did not, as we expected, predict less tolerance for cougars. Instead, the relationship we found between habitat quality for cougars and tolerance by people was positive, albeit weak and without statistical significance. We speculate that the negative correlation between proximity to carnivores and tolerance breaks down at finer spatial scales where members of a community share awareness of the general presence of carnivores and other factors determine perceptions of risk. In addition, there is the possibility that some residents choosing to live in proximity to cougar habitat may be selecting to do so to be closer to nature, e.g., not ranchers or long-term residents of rural Alberta, but newer residents who have a more tolerant view of carnivores and a stronger desire to coexist.
Our results suggest that the value people hold for large carnivores is essential for their long-term conservation in human-dominated landscapes and support the work of other authors who highlight education as an essential contributor to tolerance for carnivores (Williams et al. 2002, Manfredo et al. 2003, Naughton-Treves et al. 2003). Beyond equipping individuals to assess risk more accurately, education supports broader worldviews (NaughtonTreves et al. 2003) that allow simultaneous assessments of risk, intrinsic value, and ecosystem functions. Our work suggests that education should supply people with evidence (e.g., statistics) that supports accurate estimation of the risks posed by large carnivores as well as the importance of modified habitats (e.g., the ranchlands and exurban developments) for large carnivore conservation. These foci could improve tolerance for cougars specifically, but also the conservation of large carnivores more generally in landscapes where people and carnivores coexist.

Large carnivores appear to be remarkably adaptable to modified landscapes, and maintaining their populations does not necessarily require large areas of wilderness (Athreya et al. 2013, Chapron et al. 2014, Knopff et al. 2014, López-Bao et al. 2015). Indeed, it appears that top-down, human-caused mortality is much more limiting for some carnivore populations than bottomup, habitat-based measures of carrying capacity (Linnell et al. 2001, Chapron et al. 2014). We suggest that long-term coexistence with carnivores, including carnivore recolonization of habitats from which they have been extirpated, will require management policies that emphasize education, accurate risk assessment, and proactive prevention of conflict. At the same time, we encourage retention of diverse management tools that address conflict with large carnivores, including judicious use of lethal carnivore control, physical barriers such as fencing, and sanctions against human behaviors that increase future risk of human-wildlife conflict.

\section{Responses to this article can be read online at: http://www.ecologyandsociety.org/issues/responses. $\mathrm{php} / 8933$}

\footnotetext{
Acknowledgments:

Funding for this research was provided by the Alberta Conservation Association, Natural Sciences and Engineering Research Council of Canada, Alberta Ingenuity Fund, Shell Canada, Alberta Cooperative Conservation Research Unit, Alberta Sport, Recreation, Parks and Wildlife Foundation, Yellowstone to Yukon Foundation, Alberta Sustainable Resource Development, Rocky Mountain Elk Foundation, Rocky Fish and Game Association, the Calgary Zoo, Alberta Professional Outfitter's Society, Grand Slam Club, Foundation for North American Wild Sheep, and Safari Club International. We thank all of the field technicians who assisted us in data collection. The help of L. Hindbo, S. Hindbo, W. Anderson, C. Miller, S. Odgers, and their dogs was indispensable for the safe and efficient capture of cougars. Finally, we thank the residents of Clearwarter County, Alberta, who gave their time and effort to participate in this research.
} 


\section{LITERATURE CITED}

Alberta Transportation. 2008. Alberta traffic collision statistics 2008. Office of Statistics and Information, Government of Alberta, Edmonton, Alberta, Canada.[online] URL: https:// www.transportation.alberta.ca/Content/docType47/Production/AR2008. pdf

Anderson, C. R., Jr., F. Lindzey, K. H. Knopff, M. G. Jalkotzy, and M. S. Boyce. 2009. Cougar management in North America: Canada. Pages 41-54 in S. Negri and M. Hornocker, editors. Cougar: ecology and conservation. University of Chicago Press, Chicago, Illinois, USA.

Athreya, V., M. Odden, J. D. C. Linnell, J. Krishnaswamy, and U. Karanth. 2013. Big cats in our backyards: persistence of large carnivores in a human dominated landscape in India. PLoS ONE 8(3):e57872. http://dx.doi.org/10.1371/journal.pone.0057872

Baron, D. 2004. Beast in the garden: a modern parable of man and nature. W. W. Norton, New York, New York, USA.

Beier. P. 1991. Cougar attacks on humans in the United States and Canada. Wildlife Society Bulletin 19:403-412.

Bruskotter, J. T., and R. S. Wilson. 2014. Determining where the wild things will be: using psychological theory to find tolerance for large carnivores. Conservation Letters 7:158-165. http://dx.doi. org/10.1111/conl.12072

Burnham, K. P., and D. R. Anderson, editors. 2002. Model selection and multimodel inference: a practical informationtheoretic approach. Second edition. Springer Science, New York, New York, USA. http://dx.doi.org/10.1007/b97636

Chapron, G., P. Kaczensky, J. D. C. Linnell, M. von Arx, D. Huber, H. Andrén, J. V. López-Bao, M. Adamec, F. Álvares, O. Anders, et al. 2014. Recovery of large carnivores in Europe's modern human-dominated landscapes. Science 346(6216): 1517. http://dx. doi.org/10.1126/science. 1257553

Coleman, J. T. 2004. Vicious: wolves and men in America. Yale University Press, New Haven, Connecticut, USA.

Cougar Management Guidelines Working Group. 2005. Cougar management guidelines. WildFutures, Bainbridge Island, Washington, USA.

Decker, D. J., B. Lauber, and W. F. Siemer. 2002. Human-wildlife conflict management: a practitioners guide. Northeast Wildlife Damage Management Research and Outreach Cooperative, New York, New York, USA.

Duke, D., M. Quinn, B. Butts, T. Lee-Ndugga, and K. Wilkie. 2003. Spatial analysis of rural residential expansion in southwestern Alberta. Miistakis Institute for the Rockies, Calgary, Alberta, Canada.

Ericsson, G., G. Bostedt, and J. Kindberg. 2008. Wolves as a symbol of people's willingness to pay for large carnivore conservation. Society and Natural Resources 21:294-309. http:// dx.doi.org/10.1080/08941920701861266

Gill, R. B. 2009. To save a mountain lion: evolving philosophy of nature and cougars. Pages 5-16 in S. Negri and M. Hornocker, editors. Cougar: ecology and conservation. University of Chicago Press, Chicago, Illinois, USA.
Gore, M. L., and B. A. Knuth. 2009. Mass media effect on the operating environment of a wildlife-related risk-communication campaign. Journal of Wildlife Management 73:1407-1413. http:// dx.doi.org/10.2193/2008-343

Gotelli, N. J., and A. M. Ellison, 2004. A primer of ecological statistics. Sinauer Associates, Sunderland, Massachusetts, USA.

Holsman, R. H. 2000. Goodwill hunting? Exploring the role of hunters as ecosystem stewards. Wildlife Society Bulletin 28: 808-816

Hornocker, M. 2009. Pressing business. Pages 235-247 in S. Negri and M. Hornocker, editors. Cougar: ecology and conservation. University of Chicago Press, Chicago, Illinois, USA.

Kahneman, D., and A. Tversky. 1996. On the reality of cognitive illusions. Psychological Review 103:582-591. http://dx.doi. org/10.1037/0033-295X.103.3.582

Karlsson, J., and M. Sjöström. 2007. Human attitudes towards wolves, a matter of distance. Biological Conservation 137:610-616. http://dx.doi.org/10.1016/j.biocon.2007.03.023

Kellert, S. R., M. Black, C. R. Rush, and A. J. Bath. 1996. Human culture and large carnivore conservation in North America. Conservation Biology 10:977-990. http://dx.doi.org/10.1046/ j.1523-1739.1996.10040977.x

Knopff, A. A., K. H. Knopff, M. S. Boyce, and C. C. St. Clair. 2014. Flexible habitat selection by cougars in response to anthropogenic development. Biological Conservation 178:136-145. http://dx.doi.org/10.1016/j.biocon.2014.07.017

Knopff, K. H. 2010. Cougar predation in a multi-prey system in west-central Alberta. Thesis. University of Alberta, Edmonton, Alberta, Canada.

Knopff, K. H., A. A. Knopff, A. Kortello, and M. S. Boyce. 2010. Cougar kill rate and prey composition in a multi-prey system: influence of season, demography, and prey vulnerability. Journal of Wildlife Management 74:1435-1447. http://dx.doi.org/10.1111/ j.1937-2817.2010.tb01270.x

Knopff, K. H., N. H. Webb, and M. S. Boyce. 2013. Cougar population status and range expansion in Alberta during 1991-2010. Wildlife Society Bulletin 38:116-121. http://dx.doi. org/10.1002/wsb.369

Kruuk, H. 2002. Hunter and hunted: relationships between carnivores and people. Cambridge University Press, Cambridge, UK. http://dx.doi.org/10.1017/cbo9780511614996

Lambert, C. M. S., R. B. Wielgus, H. S. Robinson, D. D. Katnik, H. S. Cruickshank, R. Clarke, and J. Almack. 2006. Cougar population dynamics and viability in the Pacific Northwest. Journal of Wildlife Management 70:246-254. http://dx.doi. org/10.2193/0022-541X(2006)70[246:CPDAVI]2.0.CO;2

Linnell, J. D. C., J. E. Swenson, and R. Anderson. 2001. Predators and people: conservation of large carnivores is possible at high human densities if management policy is favourable. Animal Conservation 4:345-349. http://dx.doi.org/10.1017/s1367943001001408

Logan, K. A., and L. L. Sweanor. 2000. Puma. Pages 347-377 in S. Demaraias and P. R. Krausman, editors. Ecology and management of large mammals in North America. Prentice Hall, Englewood Cliffs, New Jersey, USA. 
Logan, K. A., and L. L. Sweanor. 2001. Desert puma: evolutionary ecology and conservation of an enduring carnivore. Island Press, Washington, D.C., USA.

López-Bao, J. V., P. Kaczensky, J. D. C. Linnell, L. Boitani, and G. Chapron. 2015. Carnivore coexistence: wilderness not required. Science 348(6237):871-872. http://dx.doi.org/10.1126/ science.348.6237.871-b

Manly, B. F. J., L. L. McDonald, and D. L. Thomas. 2002. Resource selection by animals: statistical design and analysis for field studies. Second edition. Kluwer Academic Publishers, Boston, Massachusetts, USA.

Manfredo, M., T. Teel, and A. Bright. 2003. Why are public values toward wildlife changing? Human Dimensions of Wildlife 8:287-306. http://dx.doi.org/10.1080/716100425

Manfredo, M. J., H. C. Zinn, L. Sikorowski, and J. Jones. 1998. Public acceptance of mountain lion management: a case study of Denver, Colorado and nearby foothills areas. Wildlife Society Bulletin 26:964-970.

Mattson, D. J., and S. G. Clark. 2009. People, politics, and cougar management. Pages 206-220 in S. Negri and M. Hornocker, editors. Cougar: ecology and conservation. University of Chicago Press, Chicago, Illinois, USA.

Naughton-Treves, L., R. Grossberg, and A. Treves. 2003. Paying for tolerance: rural citizens' attitudes toward wolf depredation and compensation. Conservation Biology 17:1500-1511. http://dx. doi.org/10.1111/j.1523-1739.2003.00060.x

Naughton-Treves, L., and A. Treves. 2005. Socio-ecological factors shaping local support for wildlife: crop raiding by elephants and other wildlife in Africa. Pages 252-277 in R. Woodroffe, S. Thirgood, and A. Rabinowitz, editors. People and wildlife: conflict or coexistence? Cambridge University Press, Cambridge, UK. http://dx.doi.org/10.1017/cbo9780511614774.017

Oregon Department of Fish and Wildlife. 2006. Oregon cougar management plan. Oregon Fish and Wildlife, Salem, Oregon, USA..

Penteriani, V., M. del Mar Delgado, F. Pinchera, J. Naves, A. Fernández-Gil, I. Kojola, S. Härkönen, H. Norberg, J. Frank, J. M. Fedriani, et al. 2016. Human behaviour can trigger large carnivore attacks in developed countries. Scientific Reports 6:20552. http://dx.doi.org/10.1038/srep20552

Riley, S. J. 1998. Integration of environmental, biological, and human dimensions for management of mountain lions. Thesis. Cornell University, Ithaca, New York, USA.

Riley, S. J., and D. J. Decker. 2002. Wildlife stakeholder acceptance capacity for cougars in Montana. Wildlife Society Bulletin 28:931-939.

Ripple, W. J., and R. L. Beschta. 2006. Linking a cougar decline, trophic cascade, and catastrophic regime shift in Zion National Park. Biological Conservation 133:397-408. http://dx.doi. org/10.1016/j.biocon.2006.07.002

Ripple, W. J., J. A. Estes, R. L. Beschta, C. C. Wilmers, E. G. Ritchie, M. Hebblewhite, J. Berger, B. Elmhagen, M. Letnic, M.
P. Nelson, et al. 2014. Status and ecological effects of the world's largest carnivores. Science 343(6167):1241484. http://dx.doi. org/10.1126/science. 1241484

Røskaft, E., T. Bjerke, B. Kaltenborn, J. D. C. Linnell, and R. Andersen. 2003. Patterns of self-reported fear toward large carnivores among the Norwegian public. Evolution \& Human Behavior 24:184-198. http://dx.doi.org/10.1016/S1090-5138(03) 00011-4

Slagle, K., R. Zajac, J. Bruskotter, R. Wilson, and S. Prange. 2013. Building tolerance for bears: a communications experiment. Journal of Wildlife Management 77:863-869. http://dx.doi. org/10.1002/jwmg.515

Terborgh, J., L. Lopez, P. Nuñez, M. Rao, G. Shahabuddin, G. Orihuela, M. Riveros, R. Ascanio, G. H. Adler, T. D. Lambert, and L. Balbas. 2001. Ecological meltdown in predator-free forest fragments. Science 294(5548):1923-1925. http://dx.doi.org/10.1126/ science. 1064397

Thirgood, S., R. Woodroffe, and A. Rabinowitz. 2005. The impact of human-wildlife conflict on human lives and livelihoods. Pages 13-26 in R. Woodroffe, S. Thirgood, and A. Rabinowitz, editors. People and wildlife: conflict or coexistence? Cambridge University Press, Cambridge, UK. http://dx.doi.org/10.1017/cbo9780511614774.003

Torres, S. G. 2005. Lion sense: traveling and living safely in mountain lion country. Second edition. Falcon Guide, Guilford, Connecticut, USA.

Torres, S. G., T. M. Mansfield, J. E. Foley, T. Lupo, and A. Brinkhaus. 1996. Mountain lion and human activity in California: testing speculations. Wildlife Society Bulletin 24:451-460.

Treves, A. 2009. Hunting for large carnivore conservation. Journal of Applied Ecology 46:1350-1356. http://dx.doi.org/10.1111/ j.1365-2664.2009.01729.x

Treves, A., and K. U. Karanth. 2003. Human-carnivore conflict and perspectives on carnivore management worldwide. Conservation Biology 17:1491-1499. http://dx.doi.org/10.1111/ j.1523-1739.2003.00059.X

Williams, C. K., G. Ericsson, and T. A. Heberlein. 2002. A quantitative summary of attitudes toward wolves and their reintroduction (1972-2000). Wildlife Society Bulletin 30:575-584.

Woodroffe, R. 2000. Predators and people: using human densities to interpret declines of large carnivores. Animal Conservation 3:165-173. http://dx.doi.org/10.1111/j.1469-1795.2000.tb00241. $\underline{x}$

Woodroffe, R. 2001. Strategies for carnivore conservation: lessons from contemporary extinctions. Pages 61-92 in J. L. Gittleman, S. M Funk, D. Macdonald, and R. K. Wayne, editors. Carnivore conservation. Cambridge University Press, Cambridge, UK. 